Yu. P. GALCHENKO ${ }^{1}$, Leading Researcher, Doctor of Engineering Sciences, Professor

V. A. EREMENKO ${ }^{2}$, Director of Research Center for Applied Geomechanics and Convergent Technologies in Mining, Doctor of Engineering Sciences, prof.eremenko@gmail.com

M. A. KOSYREVA ${ }^{2}$, Postgraduate Student

N. G. VYSOTIN ${ }^{2}$, Postgraduate Student

${ }^{1}$ Academician Melnikov Research Institute of Comprehensive Exploitation of Mineral Resources, Russian Academy of Sciences, Moscow, Russia

${ }^{2}$ College of Mining, NUST MISIS, Moscow, Russia

\title{
FEATURES OF SECONDARY STRESS FIELD FORMATION UNDER ANTHROPOGENIC CHANGE IN SUBSOIL DURING UNDERGROUND MINERAL MINING
}

The physical and energy basis for the prevalence of the modern technocratic-based civilization is the substance extracted from the Earth lithosphere in the course of formation and expansion of mineral mining and processing sector. Geophysically, any mineral mining process can be presented as progressive formation of discontinuities of zero or variable density in solid rock masses. Geomechanically, this means that manmade changes in the lithosphere initiate a secondary stress zone in the natural stress field, and the external boundary of the secondary stress zone delineates a new object in the lithosphere-the anthropogenically transformed subsoil area.

With a view to the mining safety and in decision-making on mining technologies to be applied, the optimum scale of this object is governed in each specific case by the ability of geophysical structures exposed to damage caused by mining to localize the secondary stress field zone and, in time, to involve it in the lithosphere evolution. In this regard, geomechanical safety of mining is connected with the critical scientific mission of geomechanics, namely, to disclose effect of anthropogenic load on the dynamic behavior of the lithosphere. Creation of advanced mining technologies which ensure continuous reproduction of stable dynamic structures and invoke no disastrous phenomena requires qualitative and quantitative evaluation of the rate of change in the natural stress-strain behavior of rock mass within the limits of the secondary stress field with regard to the factor of time taken by the process of complete extraction of mineral reserves.

In underground mineral mining with different methods, e.g. open stoping, room-and-pillar, backfilling, shrinkage stoping, caving of ore and enclosing rock mass [1-4], under conditions of variable physical and mechanical properties of rocks, stress-strain behavior, strata movement, faulting and in the presence of fluid-containing strata, formation of the secondary stress field is a dynamically unstable process [5-12]. For this reason, the prime studies use the method of virtual experiments with numerical models of geological and geotechnical systems, and with further verification of the results by physical simulation of the systems or by comparison with qualitative data of the in situ observations and tests.

The computations and analysis used Map3D environment and CAD for the complex 3D modeling, interpretation and visualization of strata pressure and elastic strains at the boundary of mined-out voids, stopes and chambers, as well as in pillars, using various rock mass classifications [13].

The elastic stress analysis of rocks in the secondary stress field uses the Hoek-Brown failure criterion which is the function of the maximal and minimal principal stresses and strength of rocks [14-18]. The natural stress was assumed as the lihostatic state $\sigma_{1}=\sigma_{2}=\sigma_{3}=12.3 \mathrm{MPa}$. The properties of rocks for the calculations are given in Table.

The modeling of the formation and raise of the secondary stresses used the most popular methods of underground mining [1-4 and two fundamentally new engineering approaches-frame structure and honeycomb structure mines $[19,20]$ - justified within the fundamental research program of the Russian Science Foundation, Grant No. 19-17-00034.

The general research methodology based on the understanding that geomechanical safety in underground mineral mining and associated destruction of the lithosphere is connected with overcoming of the devastating anthropogenic 
Properties of enclosing rocks after adjustment in RocData

\begin{tabular}{|l|c|}
\hline \multicolumn{1}{|c|}{ Characteristic } & Value \\
\hline Ultimate compression strength, MPa & 80 \\
\hline GSI (Geological Strength Index) & 80 \\
\hline Structural index $\mathrm{m}_{\mathrm{i}}$ & 10 \\
\hline Young's modulus, GPa & 30 \\
\hline Cohesion, MPa & 6.72 \\
\hline Internal friction angle, degree & 37.081 \\
\hline Hoek-Brown constant $m b$ & 3.858 \\
\hline Hoek-Brown constant $s$ & 0.069 \\
\hline Hoek-Brown constant $a$ & 0.501 \\
\hline Specific gravity, $\mathrm{MN} / \mathrm{m}^{3}$ & 0.025 \\
\hline
\end{tabular}

impact on the dynamic structures of the lithosphere. The analytical review of underground mining technologies (i. e. formation of anthropogenically transformed area in the subsoil) reveals a common feature of geomechanical and geotechnical processes-mineral mining in the zone of anthropogenic damage and protection of this zone from geomechanical disturbance of adjacent areas always synchronize. Hence, stoping naturally includes some secondary processes aimed to maintain dynamic equilibrium and safety in the whole geotechnical system. This means that in underground mining with conventional methods based on extensive managing and preventing strata pressure effects and waste disposal, the inevitable payment for local geomechanical safety is hazardous stresses induced in overlying rock mass and higher loss of commercial reserves in various size and purpose pillars.

Moreover, in the presence of fluid-containing reservoirs (water, oil, brines, or gases) in enclosing rock mass, mining operations are never protected from their effects and aftereffects.

Advance formation of a frame structure (in this article, mine frame structure No. $8[19,20])$ to accommodate a future mining area in the subsoil offers a real opportunity to overcome the above-specified local dilemma as this approach allows desynchronizing processes of formation and expansion of an anthropogenically damaged zone in the subsoil and protection of this zone of geomechanical disturbance of the adjacent lithosphere, which ensure safety and efficiency of mining.

This approach fleshes out a geomechanical idea on nature-like geotechnologies when the anthropogenic damage zone is anticipatorily outlined and separated from the field of the secondary changes in the geomechanical behavior of rock mass as the processes of mineral mining and overcoming of geomechanical disturbance after-effects are separated in time in this case.

The analytical studies into geological and geotechnical conditions of ore mining determined required parameters for prime modeling of various mining methods.

The modeling parameters included the height, width and length of mined-out and stoping areas in different mining methods. In the surrounding rock mass around a geotechnical system (mine), the secondary stress state is generated. The structure of this stress field is governed by the size of design elements of the mine, physical and mechanical properties of rocks, natural stresses, quality of surrounding rocks and ore, and by many other factors.

The index of the secondary stress field is assumed to be the value of the relative tensile strain $\varepsilon$ of enclosing rock mass [21-23]:

$\varepsilon=\Delta L / L$,

where $\Delta L$ is the deformation; $L$ is the initial size of the deformed object.

The microstrain $\mu \varepsilon=\varepsilon 10^{6}$.

The enclosing rock mass was estimated by the values of stability categories from I to IV, as well as by the Rock Mass Quality from Q-system and by RMR rating [24].

Laboratory tests find that the first cracks in hard rocks $[13,14]$ are observed at the tensile straining of $\mu \varepsilon=200$, which is a critical value for three-axis crack formation. It is experimentally found that the first tension cracks appear in hard rocks at the microstrains $\mu \varepsilon \approx 350$. At $\mu \varepsilon=500-800$ rock mass deforms more intensively, and roof arches and potential failure zones are formed. For this reason, the value $\mu \varepsilon=350$ is assumed as the numerical criterion for the external boundary of the secondary stress field, i.e. approximately a half of the strain value at which the first crack appear in rocks.

Before starting mining operations, the natural stress state is recorded in rocks in terms of the principal stresses $\sigma_{1}, \sigma_{2}$ and $\sigma_{3}[6]$. The natural stress state parameters are governed by many known factors [7].

Reliability of the modeling was checked using the in situ measurement data obtained by researchers from the Center for Applied Geomechanics and Convergent Technologies in Mining at NUST MISIS during field tests in such mines as Taimyrsky, Oktyabrsky, Komsomolsky, Mayak, Internatsionalny, Tashtagol, Kaz, Zum-Kholba, Irokinda, Sol-Iletsk, KMAruda, Severny, Golden Grove and Skalisty, using various methods of the stress-strain analysis in rock mass (Fig. 1).

The current theories identify natural rock mass as a structured ideal continuum, deformations in this continuum under external effects are totally reversible, and discontinuities $b$ are uniformly distributed in its volume. In such model, the excess elastic stress $\Delta \sigma_{1}$ can be found from the equation:

$g q V_{p}^{2} \eta-\Delta \sigma_{1} \omega / b=d \sigma_{1} / d t$

where $\eta$ is the strain rate in rock mass; $g=9.8 \mathrm{~m} / \mathrm{s}^{2} ; q$ is the specific gravity of rocks; $\omega$ is the stress relaxation rate.

As mining is advanced, growth of stresses slows down, and each size discontinuity is exposed to certain stress:

$\Delta \sigma_{1}=g q V_{p}^{2} \eta l / \omega$.

In this formulation, underground mining can be described as formation of discontinuities of zero density and variable volume in the lithosphere.

Each discontinuity is subjected to a certain concentrated excessive stress, and integration of the stresses at all discontinuities resultant from mining images the anthropogenic change in the stress-strain behavior of rock mass and can be denoted as the secondary stress field. The growth and strength of this field during block and sublevel caving is depicted in Fig. 2.

It is seen in Fig. 2 that the technology of mining has no observable effect on the shape and strength of the secondary stress field while the key role belongs to the shape and linear sizes of anthropogenic discontinuities-stopes. For this reason, it is possible to propose a new index for the assessment of damage of the natural stress field in the cause of 

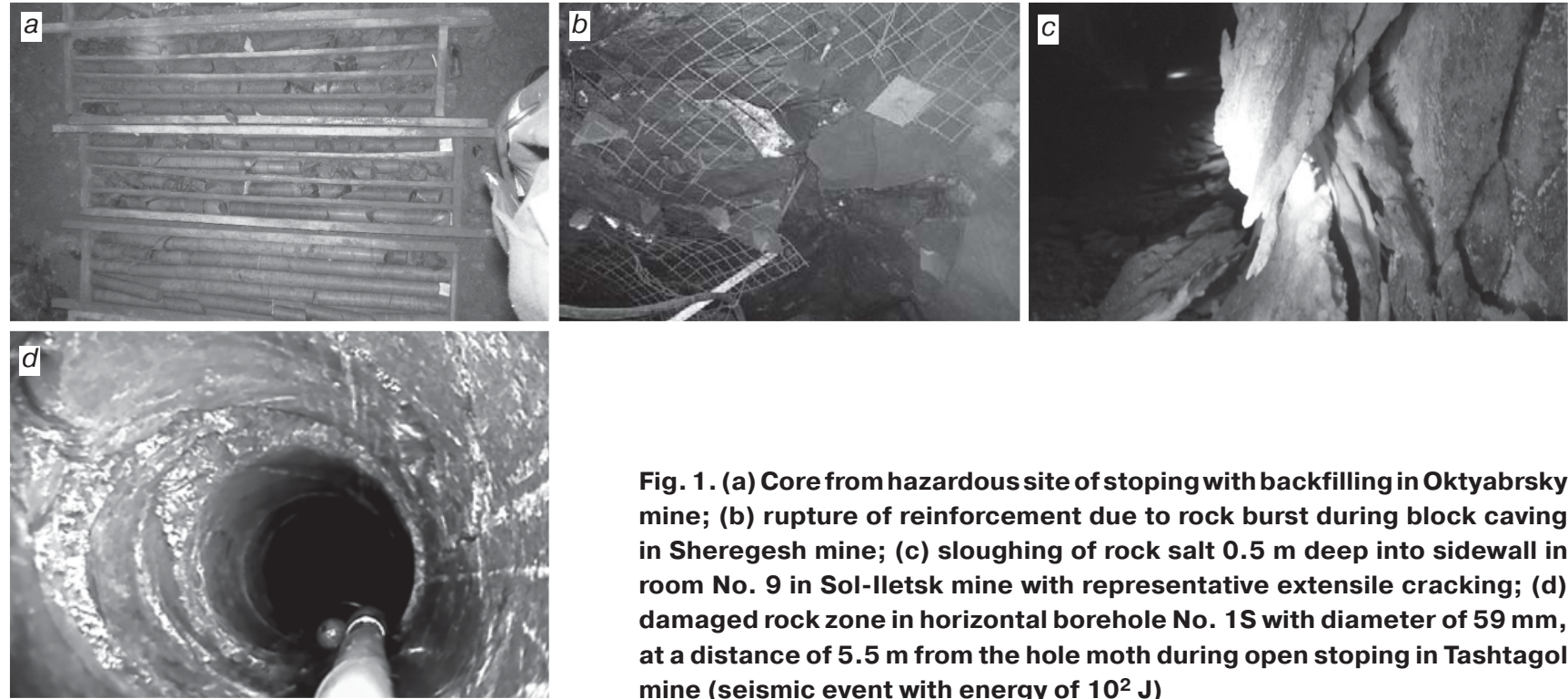

Fig. 1. (a) Core from hazardous site of stoping with backfilling in Oktyabrsky mine; (b) rupture of reinforcement due to rock burst during block caving in Sheregesh mine; (c) sloughing of rock salt $0.5 \mathrm{~m}$ deep into sidewall in room No. 9 in Sol-lletsk mine with representative extensile cracking; (d) damaged rock zone in horizontal borehole No. $1 \mathrm{~S}$ with diameter of $59 \mathrm{~mm}$, at a distance of $5.5 \mathrm{~m}$ from the hole moth during open stoping in Tashtagol mine (seismic event with energy of $10^{2} \mathrm{~J}$ )

mining -influence coefficient $E_{M}$ defined by the ratio of geometrical parameters of interacting elements:

$$
E_{M}=S_{c p} K_{K} / S_{\mu \varepsilon}
$$

where $S_{c p}$ is the external boundary area of a mine structure (structural elements), $\mathrm{m}^{2} ; S_{\mu \varepsilon}$ is the area of the tensile strain zone formed at the boundary $\mu \varepsilon=350 ; K_{K}$ is the calibration factor.

The analysis is also possible not with areas but with crosssections of stopes. In this case:

$$
E_{M p}=P_{c p} K_{K} / P_{\mu \varepsilon}
$$

where $E_{m p}$ is the local influence coefficient; $P_{c p}$ is the external boundary perimeter of a mine structure (structural elements) in a certain cross-section of the mine, $m ; P_{\mu \varepsilon}$ is the perimeter of the tensile strain zone formed at the boundary $\mu \varepsilon=350$.

The local influence coefficient $E_{M p}$ can be either higher or lower than the influence coefficient $E_{M}$ since distributions of a

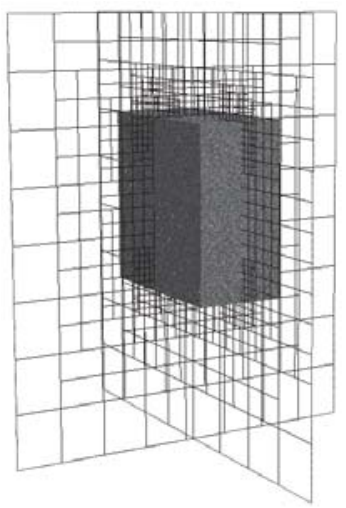

d

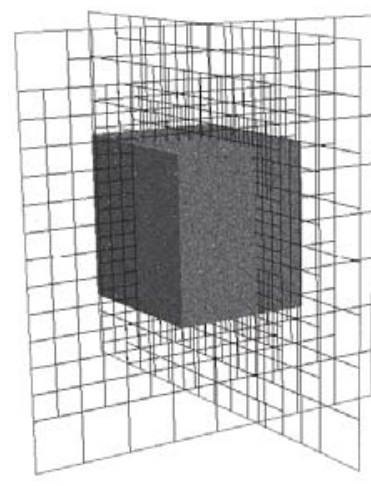

b

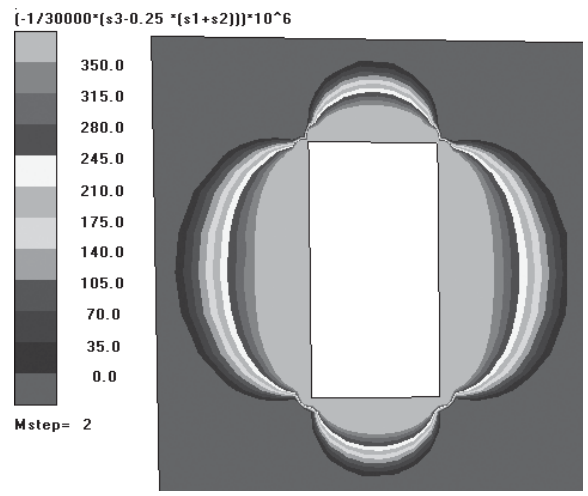

e

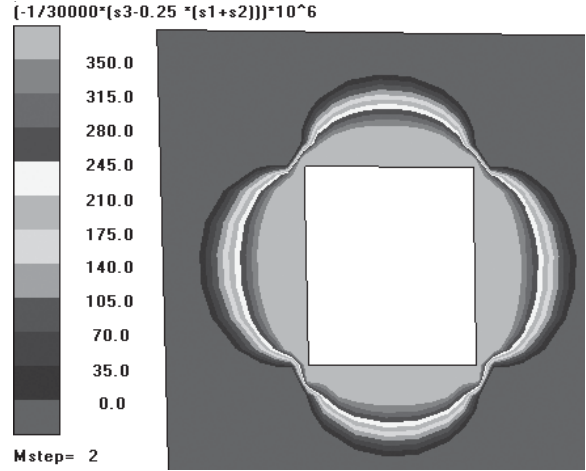

C

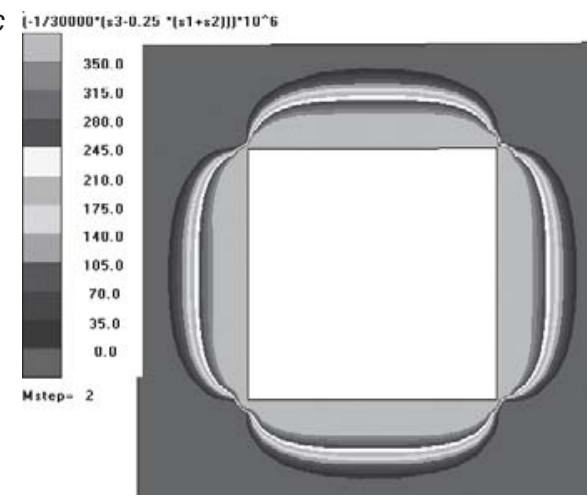

$f\left(-1 / 30000^{\times}\left(s 3-0.25^{x}(s 1+s 2)\right)\right)^{*} 10^{\wedge} 6$

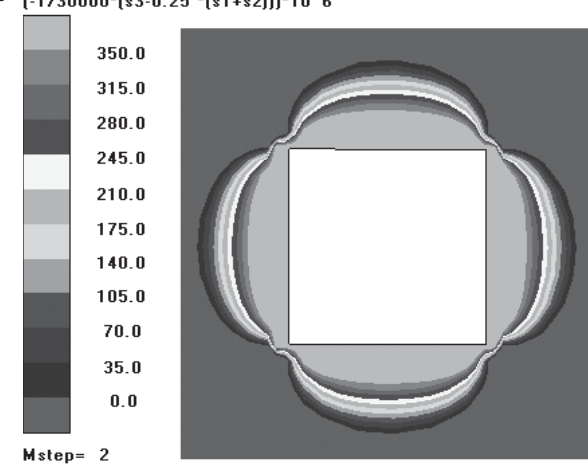

Fig. 2. Numerical modeling of secondary stress field in (a), (b), (c) block caving and (d), (e), (f) sublevel caving of single blocks: $0.0-350.0-$ microstrains $\mu \varepsilon$. 

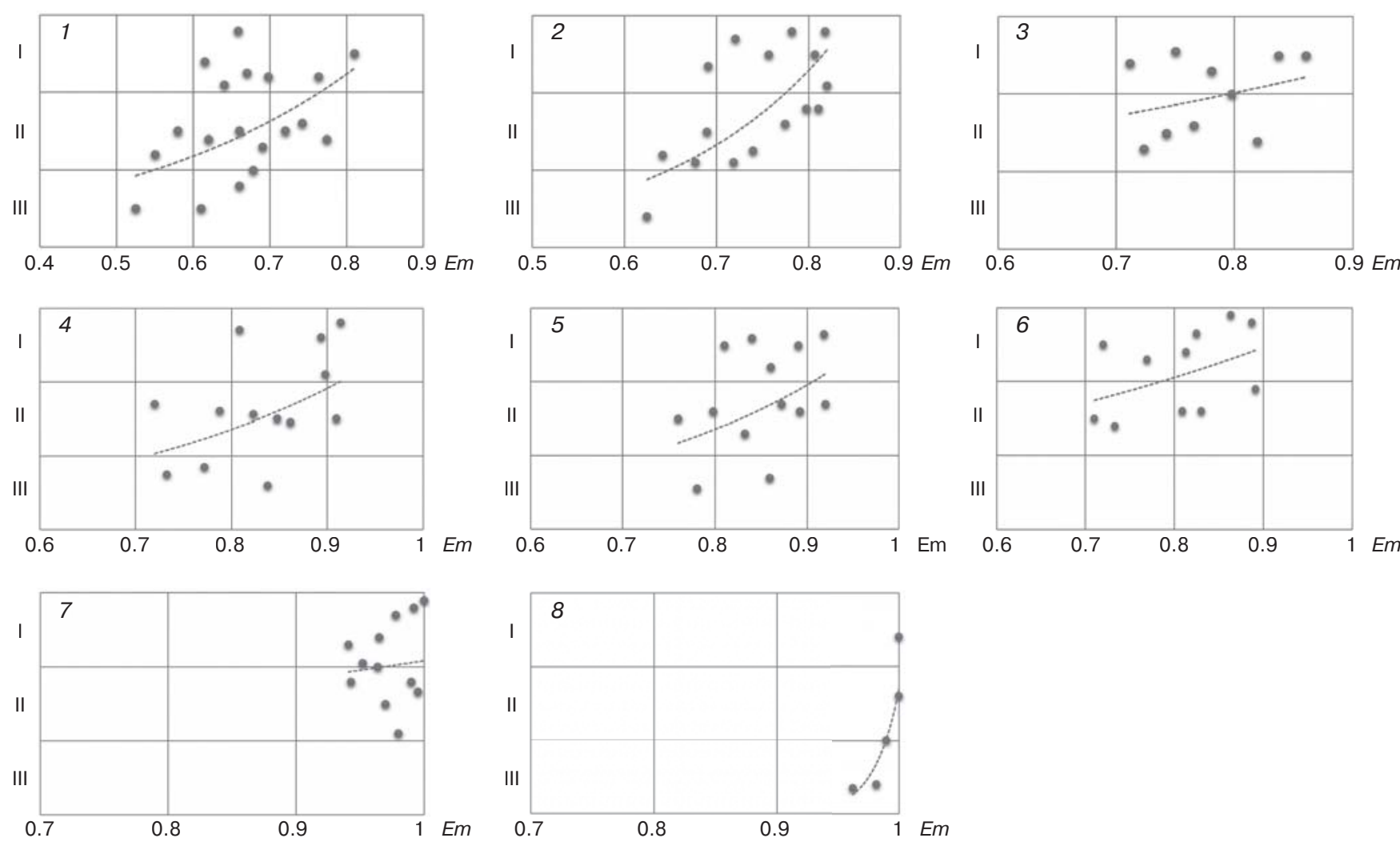

Fig. 3. Diagrams of influence exerted by conventional and new nature-like technologies of underground mining on secondary stress field:

Mining methods [1-4]: 1 - block caving; 2 - sublevel caving; 3 - open stoping with pillars; 4 - room-and-pillar mining with paste backfill; 5 - horizontal slicing with paste backfill; 6 - room-and-pillar mining; 7 - honeycomb mine structure with paste backtill, cemented backfill (gangue and waste) [19, 20]; 8 - frame mining with paste backfill, cemented backfill (gangue and waste) [19, 20]; I-III - categories of rock mass stability (stable, medium stable and unstable); Em — influence coefficient

tensile strain zones in different sections are inequivalent. The estimate in cross-section is suitable for local areas of a mineral deposit.

The calculation formulas are added with the calibration factor $K_{K}$ for the adjustment of the numerical models and values of the microstrains $\mu \varepsilon$ obtained from numerical modeling and physical simulation. The calibration uses the data of field tests carried in mines using different methods of the stress-strain behavior control in rock mass (core drilling, bench marks, endoscopic examination, etc.). When the area $S_{\mu \varepsilon}$ of the tensile strain zone formed at the boundary $\mu \varepsilon=350$ around the external boundary area of a mine structure is determined in the mine, $K_{K}=1$. For modeling, $K_{K}$ ranges from 0.2 to 0.9 and from 1.1 to 1.8 in case of the overestimated and underestimated strength characteristics of hard rock mass, respectively.

The joint analysis of the modeling and in situ observation results shows that at the boundaries of the mined-out and stoping area, concentration zones of high stresses are formed, and intensive deformation begins in rock mass; the first cracks are observed in hard rocks at the microstrains $\mu \varepsilon=350$.

When mining is advanced top down, for instance, in steeply dipping ore bodies, the concentration zones of high stresses and dynamic events in the vicinity of a mining level are related with the ore body thickness and properties of rocks for the systems of mining with caving [25]. With increasing height of mined-out area and lateral earth pressure coefficient, the maximal stress zone displaces to the bottom of the mined-out space with increasing concentration factor of horizontal stresses. The factor changes in depth of rock mass at different length/height ratios of mining sites and lateral earth pressure coefficients.

From the experimental mine tests, numerical and physical modeling, and the modeling calibration, the diagrams of the influence exerted by the parameters of the current and new nature-like technologies on mineral mining on the structure of the secondary stress field are plotted (Fig. 3) [1-4, $19,20]$.

The values of the influence coefficients in Fig. 3 for mining methods 1-6 were determined during experimental tests carried out in mines for 20 years, as well as from numerical modeling. The coefficient for the new mining methods 7 and 8 were evaluated from numerical and physical simulation, as well as when estimating stability of some structural elements in conventional mining methods, e.g. upraises. At the present time, the system for mining method 7 is designed for two deposits in Russia. There are two design variants for mining method 7: (1) bottom up drilling by Robbins or Rhino raise drill; (2) top down drilling with pilot hole reamer and with ore bypass (this method now enjoys development at the Institute of Mining, SB RAS). 
Dynamic structures are one of the basic characteristic features of the lithosphere. Mining impact and deformation processes activate dynamic structures of certain size. The cardinal stability management in rock mass subjected to anthropogenic transformation is theoretically possible through reproduction of natural dynamic structures [5]. Therefore, the proposed influence coefficient as a stability measure of a geotechnical system in a mine should tend to one.

It is found (See Fig. 3) that in block and sublevel caving $E_{v}$ varies as $0.53-0.81$ and $0.62-0.82$ in rock mass stability categories I and II(III), respectively. For stoping without backfilling, 0.71-0.86; in stoping with backfilling, 0.72-0.92 (stability categories I and II (III)). For horizontal slicing with paste backfill, 0.76-0.91 (stability categories I and II). For roomand-pillar mining, 0/72-0/89 (stability categories I and II). For nature-like geotechnologies with frame and honeycomb mine structures, the influence coefficient varies as $0.94-1$ and $0.96-1$ in rock stability categories I and II (III), respectively.

Considering the accomplished research, it has been found that the highest effect on the tensile strain zones is exerted by the mining systems with backfilling as against the same or similar systems without backfill. The best index $E m=1$ is obtained in modeling of the frame system of mining developed and recommended for difficult geology of thick and medium-thick ore bodies. Regarding the honeycomb mine structure designed for rock salt and polyhalite mines, the found characteristics of the system stability and influence on enclosing rock mass are good, too.

\section{Acknowledgments}

The study was supported by the Russian Science Foundation, Project No. 19-17-00034.

\section{References}

1. Agoshkov M. I. Designing systems and technologies for ore mining. Moscow : Nauka, 1965. 220 p.

2. New technology and systems of underground ore mining : Dedicated to the 60th anniversary of Corresponding Member of the USSR Academy of Sciences M. I. Agoshkov. Moscow : Nauka, 1965. 235 p.

3. Imenitov V. R. Processes in underground ore mining : teaching aid. Moscow : Nedra, 1984. 504 p.

4. Zubov V. P. Applied technologies and current problems of resource-saving in underground mining of stratified deposits. Gornyi Zhuirnal. 2018. No. 6. pp. 77-83. DOI: 10.17580/ gzh.2018.06.16

5. Rodionov V. N. Geomechanic's essay. Moscow : Nauchnyi mir, 1996. $126 \mathrm{p}$.

6. Rodionov V. N., Sizov I. A., Tsvetkov V. M. Basics of geomechanics. Moscow : Nedra, 1986. 286 p.

7. Borshch-Komponiets V. I. Applied geomechanics. Moscow : Gornaya kniga, 2013. 322 p.

8. Sidorov D. V., Ponomarenko T. V. Estimation methodology for geodynamic behavior of nature-and-technology systems in implementation of mineral mining projects. Gornyi Zhurnal. 2020. No. 1. pp. 49-52. DOI: $10.17580 /$ gzh.2020.01.09

9. Sidorov D., Ponomarenko T. Reduction of the ore losses in deep mining of bauxite deposits at the mines of Sevuralboksitruda.
IOP Conference Series: Earth and Environmental Science. 2019. DOI: 302. 012051. 10.1088/1755-1315/302/1/012051

10. Sidorov D. V., Ponomarenko T. V., Larichkin F. D., Vorobiev A. G. Economic justification of innovative solutions on loss reduction in the aluminium sector of Russia. Gornyi Zhurnal. 2018. No. 6. pp. 65-68. DOL: 10.17580/gzh.2018.06.14

11. Rybin V. V., Konstantinov K. N., Kagan M. M., Panasenko I. G. Methodology of integrated stability monitoring in mines. Gornyi Zhurnal. 2020. No. 1. pp. 53-57. DOI: 10.17580/ gzh.2020.01.10

12. Protosenya A. G., Verbilo P. E. Strength estimation in blocky rock mass by numerical modeling. Izvestiya vuzov. Gornyi zhurnal. 2016. No. 4. pp. 47-54.

13. Map3D. Available at: http://www.vap3d.com/ (accessed: 20.04.2020).

14. Hoek E., Brown E. T. Underground excavations in rock. London: Institute of Mining and Metallurgy, 1980.

15. Fairhurst C., Cook N. G. W. The phenomenon of rock splitting parallel to the direction of maximum compression in the neighbourhood of a surface. Proceedings of the 1st Congress of the International Society for Rock Mechanics. Lisbon, 1966. Vol. 1. pp. 687-692.

16. Jiang Q., Feng X., Song L., Gong Y., Zheg H., Cui J. Modeling rock specimens through 3D printing: Tentative experiments and prospects. Acta Mechanica Sinica. 2015. Vol. 32(1). pp. 524-535.

17. Kong L., Ostadhassan M., Li C., Tamimi N. Rock physics and geomechanics of 3D printed Rocks. ARMA 51st U.S. Rock Mechanics/Geomechanics Symposium, San Francisco, California, USA, 2017, pp. 1-8.

18. Gell E. M., Walley S. M, Braithwaite C. H. Review of the validity of the use of artificial specimens for characterizing the mechanical properties of rocks. Rock Mechanics and Rock Engineering, 2019. №. 3. pp. 1-13.

19. Trubetskoy K. N., Galchenko J. P. Nature like mining technologies: prospect of resolving global contradictions when developing mineral resources of the lithosphere. Vestnik RAN. Vol. 87, No. 4. pp. 378-384.

20. Trubetskoy K. N., Myaskov A. V., Galchenko Yu. P., Eremenko V. A. Creation and justification of convergent technologies for underground mining of thick solid mineral deposits. Gornyi Zhurnal. 2019. No. 5. pp. 6-13. DOI: 10.17580/ gzh.2019.05.01

21. Stacey T. R. A simple extension strain criterion for fracture of brittle rock. International Journal of Rock Mechanics and Mining Sciences. 1981. Vol. 18. pp. 469-474.

22. Ndlovu X., Stacey T. R. Observations and analyses of roof guttering in a coal mine. Journal of the South African Institute of Mining and Metallurgy. 2007. Vol. 107. pp. 477-491.

23. Louchnikov V. N., Sandy M. P., Eremenko V. A., Kovalenko A. A., Ivanov I. A. Procedure for determining expansion of damaged rock zone in rock mass around underground openings by numerical modeling. Gornyi Zhurnal. 2013. No. 12. pp. 11-16.

24. Barton N. Application of Q-system and index tests to estimate shear strength and deformability of rock masses. Workshop on Norwegian Method of Tunneling. New Delhi, 1993. pp. 66-84.

25. Eremenko A. A., Konurin A. I., Shtirtz V. A., Prib V. V. Identification of higher rock pressure zones in rockburst-hazardous iron ore deposits. Gornyi Zhurnal. 2020. No. 1. pp. 78-81. DOI: 10.17580/gzh.2020.01.15 国 